\title{
Estrutura Lógica como metodologia para avaliação de políticas públicas: uma análise do Pronaf
}

\author{
Evandro Henrique Figueiredo Moura da Silva \\ Universidade Estadual Paulista \\ Elaine Mendonça Bernardes \\ Universidade Estadual Paulista
}

\begin{abstract}
O Programa Nacional de Fortalecimento da Agricultura Familiar (Pronaf) incluiu agricultores familiares no quadro das políticas públicas, ao seguir as tendências das políticas da década de 1990 de democratizar acesso a recursos financeiros. A sustentabilidade foi inserida no programa. Neste estudo, o propósito geral foi analisar os objetivos do Pronaf, no contexto do desenvolvimento econômico. Considerou-se que o Pronaf não permitiria avaliar a relação entre atividades desenvolvidas e resultados obtidos pelo programa. Assim, seria inconsistente. Além de analisar documentos oficiais, outros objetivos específicos foram analisar a consistência do Pronaf e, em caso de inconsistência, propor uma matriz de estrutura lógica. Nenhum projeto foi encontrado, apenas a legislação. A análise desta não permitiu o preenchimento da matriz e isso indica inconsistência. Propôs-se uma matriz completa.
\end{abstract}

Palavras-chave: desenvolvimento regional; análise de projeto; crédito rural; sustentabilidade; administração pública.

El Marco Lógico como una metodología para la evaluación de las políticas públicas: un análisis de Pronaf

El Programa Nacional de Fortalecimiento de la Agricultura Familiar (Pronaf) incluyó agricultores familiares en el marco de las políticas públicas, al seguir las tendencias de las políticas de la década de 1990 para democratizar el acceso a los recursos financieros. La sostenibilidad se ha insertado en el programa. En este estudio, el objetivo general es analizar los objetivos del Pronaf en el contexto del desarrollo económico. Se considera que Pronaf no permite evaluar la relación entre las actividades y los resultados obtenidos en el programa. Por hipótesis, no sería coherente. Además de la búsqueda de documentos oficiales, otros objetivos específicos fueron analizar la consistencia del Pronaf, y en caso de discrepancia, proponen una matriz del marco lógico. Ningún proyecto se encuentra, sólo la legislación. Este análisis no permite el llenado de la matriz, lo que indica incompatibilidad. Se propuso una matriz completa.

Palabras clave: desarrollo regional; análisis del diseño; crédito rural; sostenibilidad; la administración pública.

DOI: http://dx.doi.org/10.1590/0034-76121439

Artigo recebido em 18 jan. 2013 e aceito em 6 fev. 2014.

Rev. Adm. Pública - Rio de Janeiro 48(3):721-743, maio/jun. 2014 


\begin{abstract}
Logical Framework as a methodology for evaluating public policies: an analysis of Pronaf The National Program for Strengthening Family Agriculture (Pronaf) has included family farmers into the scope of public policies, by following the trends of policies from the 1990s to democratize access to financial resources. Sustainability has been put into the program. In this study, the overall purpose was analyze the objectives of Pronaf, in the context of economic development. We found out that Pronaf would not allow evaluating the relation among activities conducted and results obtained by the program. Thus, it would be inconsistent. Besides analyzing official documents, other specific objectives were to analyze the consistency of Pronaf and, in case of inconsistency, propose a logical framework matrix. No project was found, only the legislation. The analyse of the latter does not allow filling the matrix and this indicates an inconsistency. A full matrix was proposed.
\end{abstract}

KeYwords: regional development; project analysis; rural credit; sustainability; public administration.

\title{
1. Introdução
}

A política de crédito rural subsidiado foi considerada o "carro-chefe" do processo de modernização parcial da agricultura brasileira entre as décadas de 1960 e 1980. Nesse período, além do subsídio farto, destacam-se: (a) o crescimento da produção agropecuária; (b) a adoção de máquinas e insumos modernos, e (c) criação da Empresa Brasileira de Pesquisa Agropecuária (Araújo e Shirota, 1987; Cardoso, 1988; Homem de Melo, 2010). Os principais beneficiários dessa política foram grandes e médios agricultores, não somente por terem aumentado a produção e a renda, mas também pela valorização do preço da terra (Araújo e Almeida, 1997). Houve ainda, segundo Rezende (1987), a capitalização do subsídio e a imobilização do capital em terra. Essa política sustentou considerável avanço na agricultura, porém discriminou os então chamados pequenos produtores e agravou a concentração de terra e renda na agricultura.

Parcela excluída do processo de modernização, pequenos produtores definidos como agricultores familiares passaram a ser objeto de política de crédito rural, na década de 1990 . Inicialmente, incluídos pela linha específica de crédito do Programa Nacional de Valorização da Pequena Propriedade Rural (Provap). Tal programa foi aprimorado e originou o Programa Nacional de Fortalecimento da Agricultura Familiar (Pronaf), que agrega linhas de crédito e políticas específicas para os agricultores familiares (Mattei, 2005), com juros subsidiados. O volume ofertado pelo Pronaf cresceu em torno de 400\% entre 2003 e 2013 (Brasil, 2013) e o custo médio do contrato, em 2002, foi superior ao da agricultura comercial em cerca de três vezes (Guanziroli, 2007). Há trabalhos que discutem impactos do Pronaf. Para ilustrar, Silva e Paula (2012), Pereira e Nascimento (2012) são trabalhos específicos para cada região e linha de crédito do Pronaf; já o de Mattei (2005) abrange todo o território nacional e linhas de crédito do Pronaf. Discutir tais resultados foge do escopo deste trabalho, que tem, por propósito geral, analisar os objetivos do Pronaf, no contexto do desenvolvimento econômico. Por hipótese, o Pronaf apresentaria inconsistência. Antes da apresentação da metodologia proposta

para avaliar este aspecto, será apresentado o referencial teórico que embasa a discussão do Pronaf no contexto do desenvolvimento. 


\section{Referencial teórico}

\subsection{0 surgimento do Pronaf e as teorias sobre desenvolvimento}

A inclusão dos agricultores familiares é uma tendência da democracia (Schultz, 1965). Especificamente no Brasil, a criação do Pronaf coincide com o período de consolidação democrática. Sen (2000) considera a democracia veículo imprescindível ao desenvolvimento de um país e que, se efetiva, ela tende a prevenir fomes e outras calamidades econômicas. Para Putnam (1993), imprescindível é que as instituições democráticas sejam eficientes na utilização dos recursos limitados e sensíveis à demanda dos cidadãos. Dessa perspectiva, considera-se o Pronaf um avanço da democracia brasileira. Tal programa seguiu as tendências das políticas da década de 1990.

A formulação do Pronaf seguiu a tendência das reformas gerenciais do Estado e, posteriormente, buscou conciliar a inclusão de agricultores com a busca pelo desenvolvimento sustentável. Essas tendências ficam evidentes ao propor formação de conselhos (estaduais e municipais) de desenvolvimento rural sustentável. Grande parte desses conselhos existe apenas formalmente, para atender às demandas burocráticas do Pronaf (Abramovay, 2001; Castilhos, 2002). Abramovay (2000), ao discutir sua formação, afirmou não existirem avaliações consistentes sobre desempenho ou sobre os planos que esses conselhos vinham elaborando. Além do aspecto de descentralização das decisões, passou-se a enfatizar a sustentabilidade, conforme se depreende da inclusão da palavra sustentável ao nome do Conselho Municipal de Desenvolvimento Rural, que consta no Decreto no 3.992, de outubro de 2001.

Por desenvolvimento sustentável entende-se a abordagem fundamentada na harmonização de objetivos sociais, ambientais e econômicos (Sachs, 2002). Importante enfatizar que o próprio termo desenvolvimento já remete à ideia de qualidade de vida, e relaciona-se com a melhora de vida e das liberdades proporcionadas (Sen, 2000). A partir de certo grau, portanto, degradação ambiental já se opõe ao conceito de desenvolvimento. Acrescentar o termo sustentabilidade ao desenvolvimento gera, entretanto, questões referentes à própria sustentabilidade do crescimento econômico. Seria o crescimento sustentável? E se não o for, pode desenvolvimento econômico ocorrer sem crescimento econômico? Aprofundar-se nestas questões não é objetivo aqui, mas algumas ideias serão sintetizadas a seguir.

Ruttan (2001) ilustrou a discussão sobre sustentabilidade do crescimento com o debate entre ecologistas e cientistas sociais de um lado versus economistas e defensores da tecnologia. Mantidos os níveis de população e consumo do final dos anos de 1960, bem além da capacidade sustentável do globo, os recursos seriam exauridos, tornando o planeta inabitável, defendiam os ecologistas (malthusianos) liderados por Erlich. Simon lançou-lhes o desafio ao solicitar que escolhessem qualquer produto natural e selecionassem qualquer data no futuro na qual ele se tornaria escasso. Argumentou este último que, se o recurso estava para tornarse mais escasso, com o crescimento da população mundial o preço deveria crescer. Ehrlich e seus colegas aceitaram o desafio, assinaram um contrato e perderam US $\$ 576,07$, pois os preços dos produtos escolhidos estavam, ao final da década, mais de $40 \%$ mais baixos. A interpre- 
tação de Ehrlich, de acordo com Ruttan, foi a de que haviam errado na escolha dos produtos e na data. O debate na literatura está, entretanto, longe de chegar ao fim. No presente século, as preocupações ambientalistas ganham cada vez mais espaço na agenda de pesquisadores e tomadores de decisão.

Ainda que haja discordância, por parte principalmente de ecologistas e sociólogos sobre a necessidade do crescimento, neste trabalho, admite-se o crescimento como condição necessária, mas não suficiente para o desenvolvimento. Entende-se, que, para o Brasil, não se pode abrir mão do crescimento econômico. Essa posição está em conformidade com a Conferência de Estocolmo e o Encontro de Founex, de acordo com Sachs (2002), nos quais se entendeu que crescimento zero deterioraria a situação dos mais pobres. Essa posição teria sido mantida, também, na conferência do Rio, em 1992. Quanto a indicadores de sustentabilidade, Veiga (2005) discute as possibilidades e lembra que sem um bom termômetro de sustentabilidade, o mais provável é que todo mundo continue a usar apenas índices de desenvolvimento quando não de crescimento. Autor que tradicionalmente tem posições diferentes de Veiga, Alves (2012) ressalta que a preservação ambiental caminha junto com a tecnologia. Uma vez que toda tecnologia produz desgaste para o meio ambiente, tecnologia sustentável, concordando com este último autor, é aquela que minimiza o desgaste. Emerge daí a necessidade de instrumentos que viabilizem a adoção dessa tecnologia sem perder de vista a necessidade do crescimento econômico.

Ao admitir o crescimento como necessário para o desenvolvimento do País, o leque que se abre para discuti-lo é amplo. Mais uma vez, cabe apenas sintetizar importantes referências. Stern (1994) revisou as teorias do crescimento econômico. Nos modelos dos anos de 1950 e 1960, apenas a tecnologia tinha potencial de gerar aumentos de longo prazo na produção per capita, uma vez que se pressupunham retornos constantes à escala. O modelo de Solow (1956, 1957) influenciou os modelos de crescimento econômico desenvolvidos no período mencionado. Esse modelo foi construído sobre os modelos de Harrod (1939) e Domar (1946) e foram "o ponto de partida para teorias de crescimento endógeno" (Stern, 1994:52). Solow (1957) considerou "mudança tecnológica" todo tipo de mudança na função de produção. Até mesmo melhorias no nível de educação da mão de obra estariam incluídas nesse conceito. A expansão do modelo de Solow permitiu a inclusão do progresso tecnológico na análise.

Construir modelos de análise do crescimento econômico no qual este fosse produto de decisões de agentes e políticas de governo era o objetivo de autores que formularam os chamados modelos de crescimento endógeno. Esta é opinião de Stern (1994), ao discutir tais modelos. Lucas (1988) é talvez a principal influência nesses modelos. Fundamentalmente, a acumulação do conhecimento, nos modelos iniciais de crescimento endógeno, dirige o crescimento a longo prazo (Romer, 1986). Para Ruttan (2001), Romer (1990) seguiu Lucas ao enfatizar a importância do capital humano em desenvolver novos conhecimentos e tecnologia. Romer lembra que o modelo de crescimento neoclássico explica o crescimento em termos de interações entre tecnologia e insumos convencionais e tal autor volta-se para a contribuição das ideias como principal fonte de sua teoria de crescimento (Romer apud Ruttan, 2001:26). Nessa linha de raciocínio, torna-se imprescindível a geração de ideias que 
conciliem a necessidade de crescimento do Brasil com a utilização de tecnologias sustentáveis pelo produtor familiar.

Ressalta-se que autores neoclássicos desconsideraram a importância do capital natural (Prugh, 1995). Por capital natural, entende-se "uma extensão da tradicional noção econômica de capital, que é geralmente definida como meios de produção manufaturados, isto é, máquinas, equipamentos, ferramentas, construções, etc.” (Prugh, 1995:51). Autores neoclássicos estariam, segundo Prugh (1995), assumindo que o capital "feito pelo homem" substituiria os recursos naturais. O próprio Solow, de acordo com Prugh, teria minimizado a importância do capital natural de maneira bastante radical. Posteriormente, Solow teria moderado sua opinião, ao contrário de outros autores neoclássicos, ainda segundo Prugh. Para tal autor, as condições que permitiram a evolução da escola neoclássica (como população bem pequena para vastos recursos naturais disponíveis) não existem mais, e, portanto, sugere uma perspectiva de economia ecológica. Merece aqui um importante ponto em defesa dos neoclássicos. É de autoria de um deles, Stern, o relatório que alerta para a urgência de medidas referentes ao aquecimento global. Se não agirmos, de acordo com Stern (2006), os custos e riscos da mudança climática equivalerão a perder pelo menos 5\% do produto interno bruto global anualmente e para sempre.

Além da maior ênfase em análises relacionadas ao capital natural, a partir dos anos 1990 cresceram as preocupações com aspectos sociais do desenvolvimento. O seminal trabalho de Putnam (1993), que retomou o conceito utilizado por Coleman (1990), é a referência mais importante. Segundo Abramovay (2000), o conceito de capital social apareceu como um instrumento para explicar o dilema neoclássico da ação coletiva. Esse dilema trata dos conflitos do interesse individual em torno da riqueza comum, como exemplo, os recursos ambientais (Campos, 2004). Tais conflitos tenderiam a superexplorar os recursos de bem público, consequentemente, resultariam no rápido esgotamento desses (Meyer e Braga, 2007). A solução desse dilema não poderia vir por meio de mudanças técnicas, mas por interferência institucional. Essa interferência relaciona-se com a eficiência institucional, que pode ser favorecida pelo estoque de capital social. Putnam (1993) considera o engajamento cívico, a cooperação e a confiança mútua essenciais para a formação de capital social. Capital social, para Putnam, diz respeito a características da organização social, como confiança, normas e sistemas, que contribuam para aumentar a eficiência da sociedade, facilitando as ações coordenadas. Entende-se que a formação de capital social poderia contribuir com a diminuição da degradação ambiental, pois cidadãos estariam mais dispostos à cooperação mútua em benefício dos bens comuns.

Stern (1994) lembra que as teorias dos anos de 1950 e 1960 eram voltadas a explicar o crescimento dos países desenvolvidos, enquanto, para os países mais pobres, era dada atenção à análise setorial, principalmente ao papel da agricultura no desenvolvimento. Nos países desenvolvidos, o enfoque era para aumentos na produção, vistos como resultantes do acúmulo de capital, população e mudanças tecnológicas. Quanto à análise da agricultura, os modelos de dois setores foram, de acordo com Alves (1997), um instrumento intelectual poderoso para justificar as políticas de industrialização forçada, em curso àquela época, que 
tanto discriminaram a agricultura. Esse autor lembra que programas para agricultura familiar têm por objetivo a transformação de agricultura tradicional em moderna. Muito da agricultura tradicional brasileira, ainda de acordo com Alves (1997), em face dos fatores clima, solo e capital humano, não satisfaz as condições de transformação e sugere como mais apropriados apenas os programas de "bem-estar". De fato, nestes casos extremos, é a melhor aplicação de recursos públicos. Este é um ponto em que Veiga (2001) discorda veementemente de Alves, inclusive porque entende que a migração, quando ocorre, não é para cidade e sim para vilas ou vilarejos que ainda seriam, sob outros critérios, considerados áreas rurais.

A análise do papel da agricultura no desenvolvimento leva ao debate sobre a transformação de agricultura familiar tradicional em familiar moderna, como estratégia de desenvolvimento. Considerando-se que a geração de empregos é quase sempre um ponto importante indicado por alguns autores na defesa da agricultura familiar, cabe aqui levantar dois pontos sobre a fragilidade desse argumento, quando o objetivo é desenvolvimento: (a) o emprego neste setor não custa menos do que em outros setores (Alves, 1997); (b) sendo a diferença entre agricultura tradicional e moderna, fundamentalmente, o não uso dos insumos modernos pela primeira, então, para se manter empregos no campo, a produção estaria condenada a não ser mecanizada. A modernização passaria, portanto, necessariamente, pela implantação de atividades de uso intensivo de mão de obra. É o caso da opção por produtos mais elaborados, a serem comercializados com selo da Agricultura Familiar, para os quais há, de fato, um nicho de mercado. Emergem, então, dificuldades quanto a questões sanitárias que exigem investimentos em capital humano no campo. Por fim, outros argumentos referentes ao papel da agricultura familiar no desenvolvimento mereceriam uma discussão. Cabe aqui, apenas, registrar que, com relação à geração de empregos, se a opção recair sobre a intensificação e/ ou sofisticação da produção, políticas importantes precisam ser implementadas. O foco de tais políticas deve ser preparar os produtores para a utilização de novas tecnologias e adequação às exigências sanitárias.

Quanto ao desenvolvimento rural, a qualidade de vida depende da criação de empregos em atividades não relacionadas à produção agropecuária em si, no meio rural - entendido como o espaço que inclui pequenas cidades distantes de grandes centros e vilarejos. Nesse ponto relacionado a empregos na área rural, autores de diferentes linhas de pensamento como Schuh e Veiga convergem. Para Schuh (1998), a redução do número de empregos na agricultura é uma "lei de ferro", tal como Johnston e Mellor (1961) preconizaram ao analisar o papel da agricultura no desenvolvimento. Ao tratar de desenvolvimento rural, além de, constantemente, enfatizar a necessidade de investimentos em educação e saúde, Schuh (1973, 1998) defendia a criação de empregos não agrícolas na área rural. Por outro lado, Veiga (2001), crítico da visão neoclássica sobre o papel da agricultura mencionada, também defende a criação de empregos não agrícolas na área rural, mas vê na diversificação da agricultura local uma fonte para a geração desses empregos. Assim, no presente estudo, o conceito de desenvolvimento rural sustentável vai bem além da preocupação com meio ambiente. Inclui investimentos em educação e saúde, bem como a necessidade de geração de empregos não ligados diretamente à produção agropecuária, ainda que, em muitos casos, fortemente 
dependentes do sucesso dessas na área rural. Essa visão, ao que parece, não está devidamente incorporada no Pronaf. A seguir, os objetivos específicos deste trabalho.

\subsection{Objetivos específicos}

Elaborar e analisar políticas públicas voltadas para o crescimento e desenvolvimento sustentável torna-se altamente relevante diante do conhecimento acumulado sobre o tema. Todavia, a elaboração precisa ser realizada de forma a possibilitar futuras avaliações. No caso do Pronaf, mudanças ocorreram, ao longo dos anos, aparentemente como resposta a pressões para inclusão de outros grupos de produtores e ampliação do volume de crédito. Ainda que necessárias, o ponto é que não há indicações de que tais mudanças tenham sido resultado de uma análise comparativa entre resultados previamente estabelecidos e resultados obtidos, ou ainda do cumprimento de alguma etapa predeterminada. Esses aspectos são indicativos da presença de lacunas na elaboração do Pronaf, o que caracterizaria inconsistência, de acordo com o método descrito a seguir.

O presente estudo parte da hipótese de que, especificamente com relação ao Pronaf, não houve, na elaboração, uma preocupação para com a consistência do programa em si. A literatura sobre elaboração e análise de projetos apresenta uma metodologia para avaliar a consistência. Trata-se do método da estrutura lógica. Ele apresenta a vantagem de expor os objetivos de um projeto em ordenação lógica e de fácil visualização. Segundo Bernardes e Peres (2006), essa metodologia permite estabelecer a relação lógica "se A, então B". É um ponto forte do método a exigência de explicitação dos pressupostos do projeto. Os pressupostos são fatores que fogem do controle tanto do administrador como do formulador do projeto. Sua explicitação torna possível avaliar o risco envolvido no projeto. A principal limitação talvez seja não considerar, na análise, aspectos qualitativos de um projeto. Embora o Pronaf não seja um projeto e sim um programa, considerou-se que uma análise dele, a partir da referida metodologia, possa colaborar para a melhor elaboração de programas voltados ao desenvolvimento rural. Por evidenciar pontos que passam despercebidos por formuladores de políticas públicas não familiarizados com análises de projetos, a análise é relevante.

Agências de desenvolvimento internacionais utilizam, para análise de projetos, o método da matriz de estrutura lógica. Segundo Coleman (1987), essas agências de desenvolvimento ou de ajuda humanitária adotaram, dentro de seus próprios sistemas operacionais, essa metodologia. No entanto, Coleman relata que existe uma grande burocracia que dificulta o acesso a esse material. E quando disponível, geralmente, o material é prolixo, extremamente detalhado e profundamente enraizado dentro dos procedimentos operacionais exclusivos de cada agência, o que dificultou a difusão dessa metodologia. Tal metodologia foi utilizada para analisar projetos de desenvolvimento dos vales do rio Tietê e Paraná no estado de São Paulo (Bernardes, 2002; Bernardes e Peres, 2006) e projetos voltados ao empreendedorismo rural (Peres, Canziani e Guimarães, 2009). Será apresentada a metodologia da estrutura lógica, por se adequar à análise a que se propõe no presente estudo, que consistiu em: (a) pesquisar 
documentos oficiais sobre o Pronaf; (b) analisar a consistência do Pronaf, e em caso de inconsistência, (c) propor uma matriz de estrutura lógica que o tornasse consistente.

\section{Metodologia}

No desenvolvimento desse trabalho, buscaram-se informações sobre o Pronaf nos endereços eletrônicos (sites) do Palácio do Planalto (Decretos no 1.946 e no 3.200), Banco Central do Brasil (Bacen) - Manual de Crédito Rural — e do Ministério do Desenvolvimento Agrário (MDA) - cartilhas do Pronaf. Contactou-se, também, profissionais que, de alguma maneira, trabalham com o Pronaf: (a) docentes de instituições públicas (Universidade Estadual Paulista "Júlio de Mesquita Filho" e Universidade de São Paulo); (b) engenheiros agrônomos dos órgãos oficiais de assistência e de extensão rural autorizados a emitir a Declaração de Aptidão ao Pronaf (DAP); (c) funcionários da Superintendência Federal do Ministério do Desenvolvimento Agrário no Estado de São Paulo, e (d) profissionais do Banco do Brasil, da área de crédito rural. Foi-lhes questionado se: (i) tinham conhecimento da existência de algum documento detalhado sobre os objetivos e metas do Pronaf, além da legislação referente; (ii) existem, de fato, os Conselhos Municipais de Desenvolvimento Rural Sustentável (CMDRS) nos municípios que atuavam; (iii) conheciam outros municípios onde esses conselhos funcionassem de forma realmente participativa, e (iv) se conheciam claramente a legislação referente ao Pronaf. Obtidas tais informações, se iniciou a análise do Pronaf pela metodologia da estrutura lógica.

Admitindo-se que o Pronaf possa ser visto como um projeto de desenvolvimento — por ser um instrumento de mudança - , é de se esperar que os meios de mudanças estejam relacionados aos objetivos do projeto de desenvolvimento. Para a escolha desses objetivos, algumas metodologias são sugeridas na literatura, dentre essas está a árvore de objetivos. Essa metodologia permite que, mediante a discussão de determinados problemas, sejam definidos objetivos e estratégias de ação (Jackson, 1997). Segundo Jackson, uma vez definidos os objetivos, esses podem ser transportados para a matriz da estrutura lógica. O preenchimento da matriz é feito a partir da análise da estratégia, e pode tornar mais lógica a relação entre os objetivos propostos. Ressalta-se que, mesmo não tendo sido elaborada através dessa metodologia, a matriz pode ser criada para avaliação. Este foi o caso do presente estudo.

\subsection{Metodologia da estrutura lógica}

A metodologia da estrutura lógica consiste em representar um projeto na forma de uma matriz $4 \times 4$. Os elementos dessa matriz permitem a avaliação do projeto em questão, através da utilização de critérios relacionados à análise de sistemas, à responsabilidade gerencial do programa e ao método científico. Assim, um projeto é considerado consistente quando todas as células da matriz da estrutura lógica forem preenchidas; caso contrário, 
há inconsistência. A matriz da estrutura lógica ordena os objetivos de um projeto em quatro níveis hierárquicos: (i) insumos (atividades); (ii) produtos; (iii) propósitos, e (iv) fim. A explicação desses níveis será discorrida a seguir, mas, antes, uma exemplificação pode torná-la mais assimilável.

Como exemplo do uso da metodologia, seja o problema da má distribuição da renda. Depois de discutir o problema no país "X", chega-se à conclusão de que é preciso melhorar a educação nesse determinado país. Para isso, aplica-se a metodologia árvore de objetivos descrita por Jackson (1997) para encontrar uma estratégia e definir os objetivos. Dentre os objetivos definidos, suponha que seja delegada, entre outras funções, a criação de uma metodologia inovadora de ensino. Essa seria uma das atividades a realizar, que na matriz da estrutura lógica denomina-se "insumo", sendo o nível hierárquico mais baixo dos objetivos. Suponha que, após administrar esse e outros insumos, sejam criadas escolas de período integral para atender os estudantes desse país, então esse seria um exemplo de "produto". O produto, por si só, não tem valor e não justifica o projeto, pois o que realmente interessa é melhorar a educação no país "X". Esse é um objetivo de nível hierárquico mais elevado que é definido como "propósito", o qual se almeja alcançar quando os produtos são concretizados. Em suma, dentro do próprio projeto têm-se três níveis: insumos, produtos e propósitos.

O quarto nível na estrutura lógica é o objetivo de mais alta hierarquia, chamado "fim" que, no exemplo da distribuição de renda, seria melhorar a distribuição no país "X". No entanto, o fictício projeto de "melhorar a educação" é uma das condições para que se alcance esse fim, mas pode ser que não seja suficiente, sendo necessário que outros projetos sejam elaborados e bem-sucedidos. Esses níveis hierárquicos constituem o resumo narrativo da matriz da estrutura lógica e estão sintetizados no quadro1.

Quadro 1

A matriz de Estrutura Lógica

\begin{tabular}{|l|l|l|l|}
\hline \multicolumn{1}{|c|}{$\begin{array}{c}\text { RESUMO } \\
\text { NARRATIVO }\end{array}$} & $\begin{array}{c}\text { INDICADORES } \\
\text { OBJETIVOS }\end{array}$ & MEIOS DE VERIFICAÇÃO & $\begin{array}{c}\text { PRESSUPOSTOS } \\
\text { IMPORTANTES }\end{array}$ \\
\hline Fim & " $\mathrm{n}$ " indicadores & meios de verificação dos " $\mathrm{n}$ " indicadores & \\
\hline Propósito & " $\mathrm{x}$ " indicadores & meios de verificação dos " $\mathrm{x}$ " indicadores & Pressupostos \\
\hline Produtos & " $\mathrm{y}$ " indicadores & meios de verificação dos " $\mathrm{y}$ " indicadores & Pressupostos \\
\hline Insumos & " $z$ " indicadores & meios de verificação dos " $z$ " indicadores & Pressupostos \\
\hline
\end{tabular}

Fonte: Adaptado de Jackson (1997).

Definidos os objetivos que formam o "resumo narrativo", outro fator de grande importância são os "pressupostos". Os pressupostos são fatores que fogem do controle tanto do administrador como do formulador do projeto. No entanto, esses pressupostos devem estar previstos no projeto, pois aumentam a possibilidade de êxito e confiança no mesmo. Os "in- 
dicadores objetivos" acrescentam profundidade e compreensão ao projeto. Segundo Jackson (1997), esses indicadores devem ser: (a) mensuráveis; (b) exequíveis; (c) relevantes; (d) precisos; (e) sensíveis, e (f) devem ser capazes de fornecer informação em tempo hábil. Os chamados "meios de verificação", que também devem estar especificados no projeto, devem mostrar como ou onde encontrar os dados para medir os indicadores objetivos.

\section{Resultados e discussão}

Para a avaliação do Pronaf, pesquisaram-se documentos em páginas da internet, nas próprias instituições (Ministério do Desenvolvimento Agrário e Instituto Nacional de Colonização e Reforma Agrária) responsáveis pela execução do referido programa, e por meio de consultas a profissionais que, de alguma maneira, trabalham com o programa. Tanto profissionais da extensão quanto outros técnicos das instituições mencionadas, todos afirmaram desconhecer qualquer documento que explicasse mais que a legislação, sobre os objetivos e metas do Pronaf. A partir dessa constatação, montou-se uma matriz da estrutura lógica com o material e legislação disponível (quadro 2). Durante o preenchimento da matriz, notou-se que apenas a primeira coluna - resumo narrativo - poderia ser preenchida. Ela representa a descrição, em ordenação hierárquica, dos objetivos e foi construída com base na metodologia descrita.

Verificado que as outras colunas não poderiam ser preenchidas, com os dados disponíveis, constatou-se que o programa apresenta inconsistência pelo critério da matriz de estrutura lógica. Não permite verificação quantitativa dos seus objetivos, e, ao não explicitar pressupostos, compromete a análise lógica "Se A, então B", daí a inconsistência. Propôs-se, então, o preenchimento das demais colunas (quadro 2). Possíveis pressupostos foram explicitados, além de indicadores objetivos e meios de verificação para o Pronaf. Com relação ao resumo narrativo do programa, apenas uma alteração foi sugerida: na matriz proposta inverteu-se o "propósito" com o "fim". Essa inversão será discutida adiante. A presente discussão seguirá a ordem crescente do nível hierárquico da matriz. 


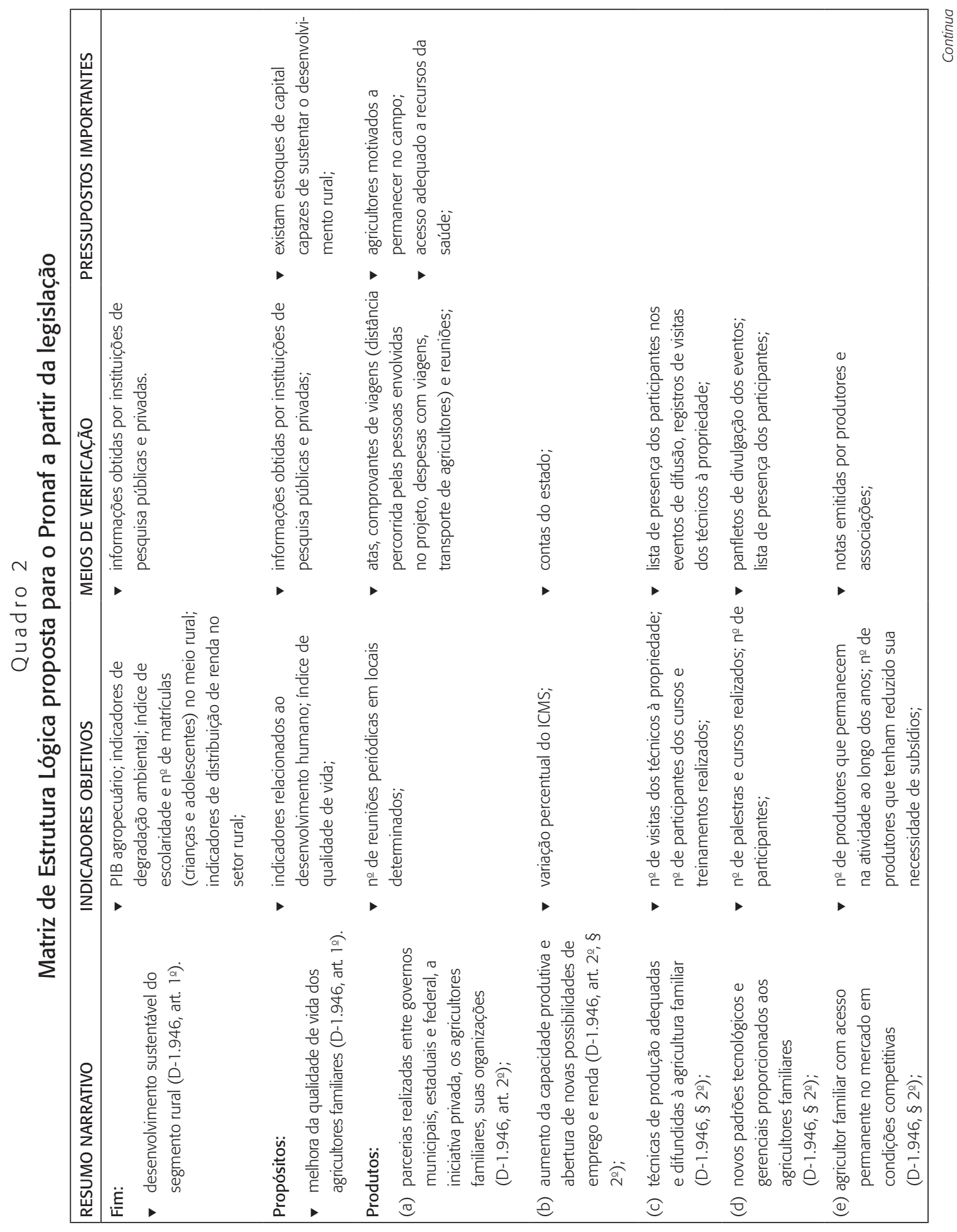

Rev. Adm. Pública - Rio de Janeiro 48(3):721-743, maio/jun. 2014 


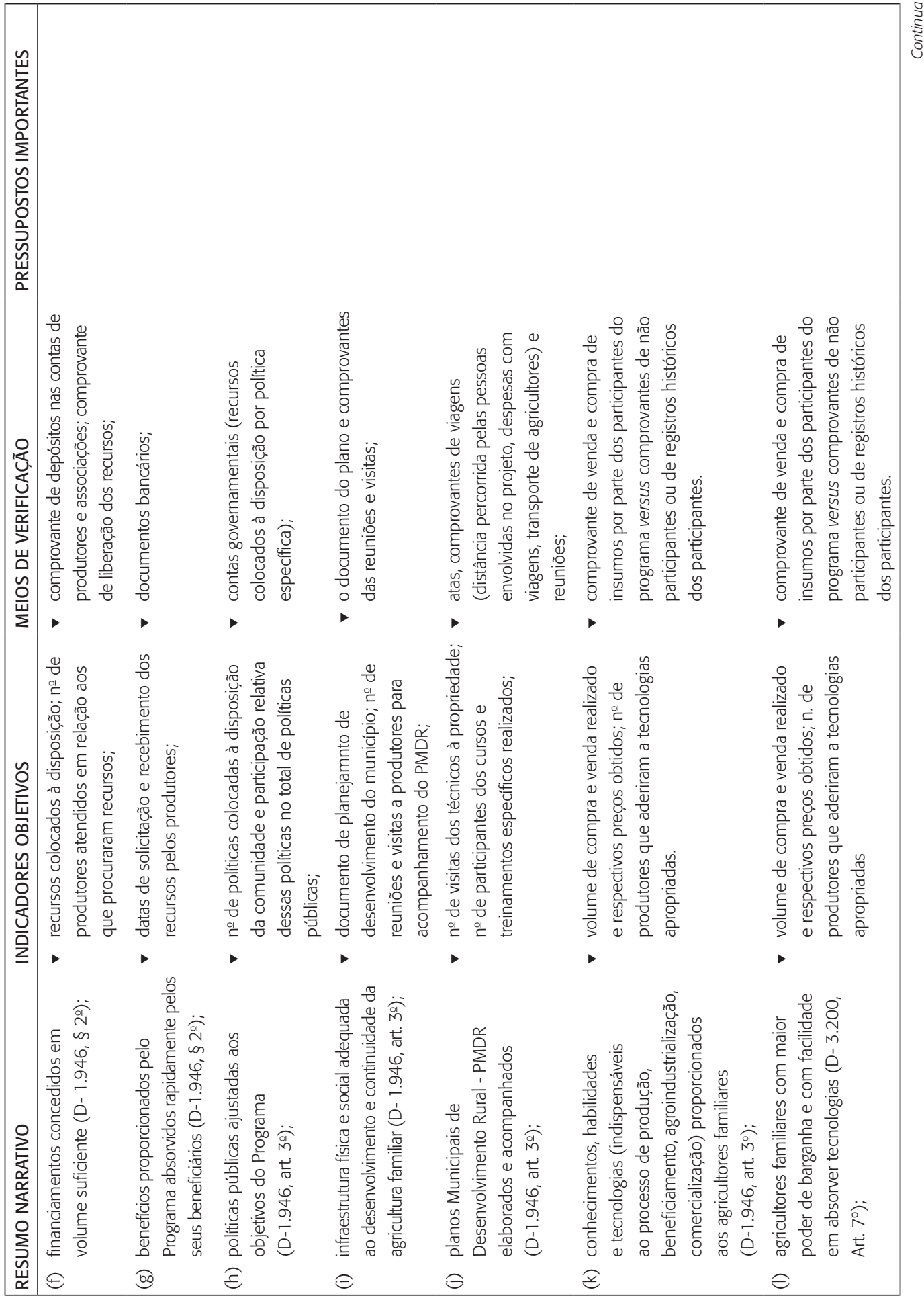

Rev. Adm. Pública - Rio de Janeiro 48(3):721-743, maio/jun. 2014 


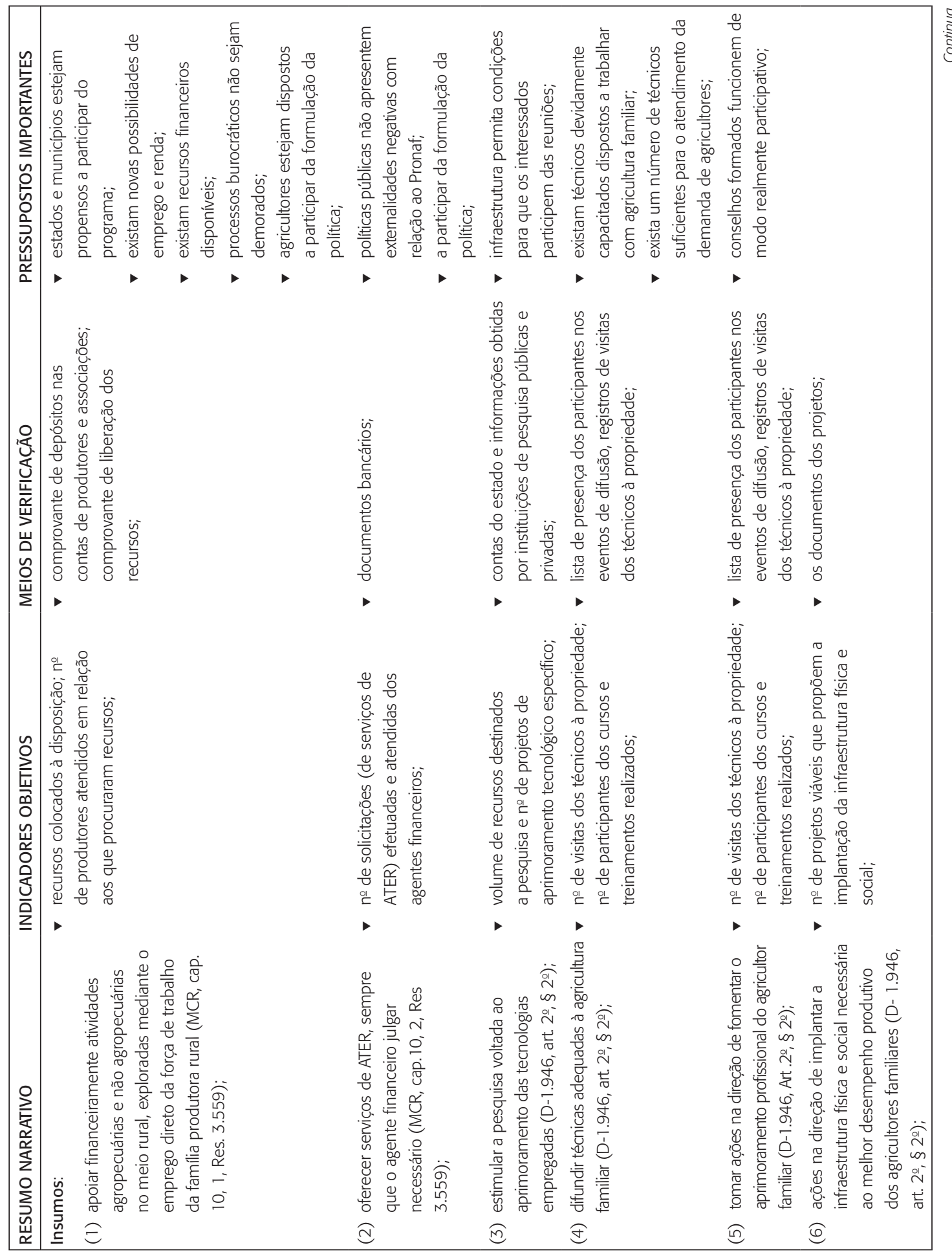

Rev. Adm. Pública - Rio de Janeiro 48(3):721-743, maio/jun. 2014 


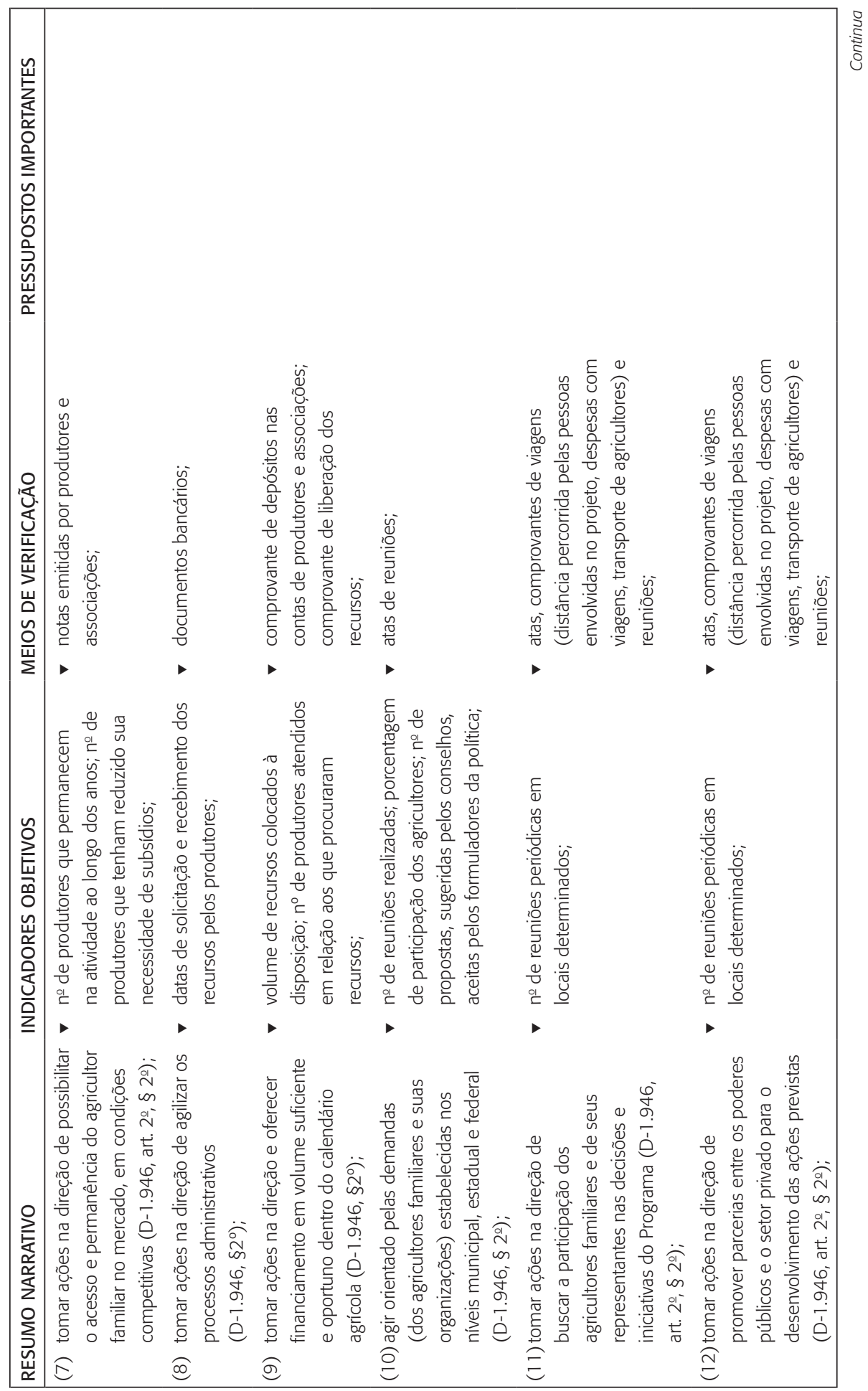

Rev. Adm. Pública - Rio de Janeiro 48(3):721-743, maio/jun. 2014 


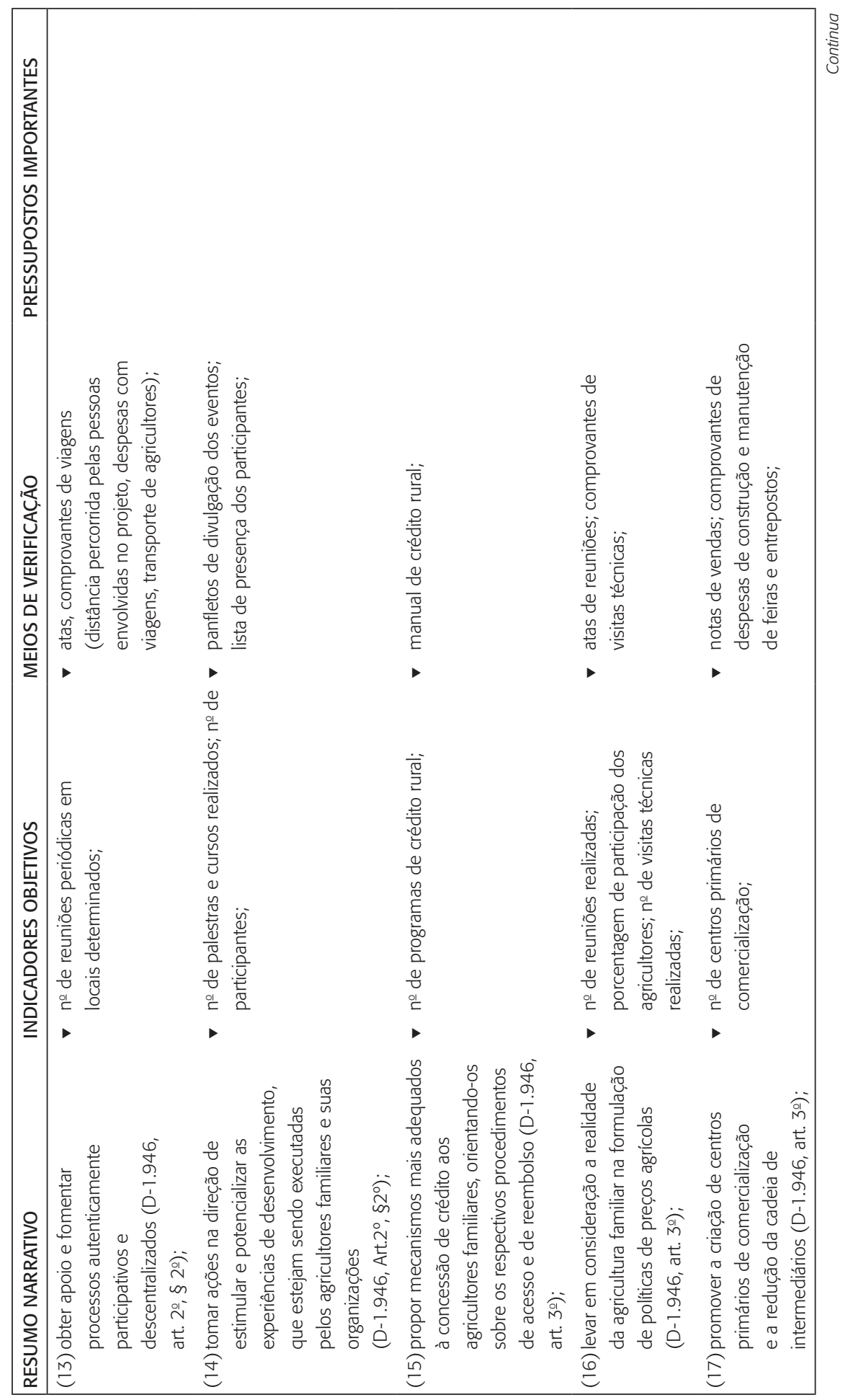

Rev. Adm. Pública - Rio de Janeiro 48(3):721-743, maio/jun. 2014 


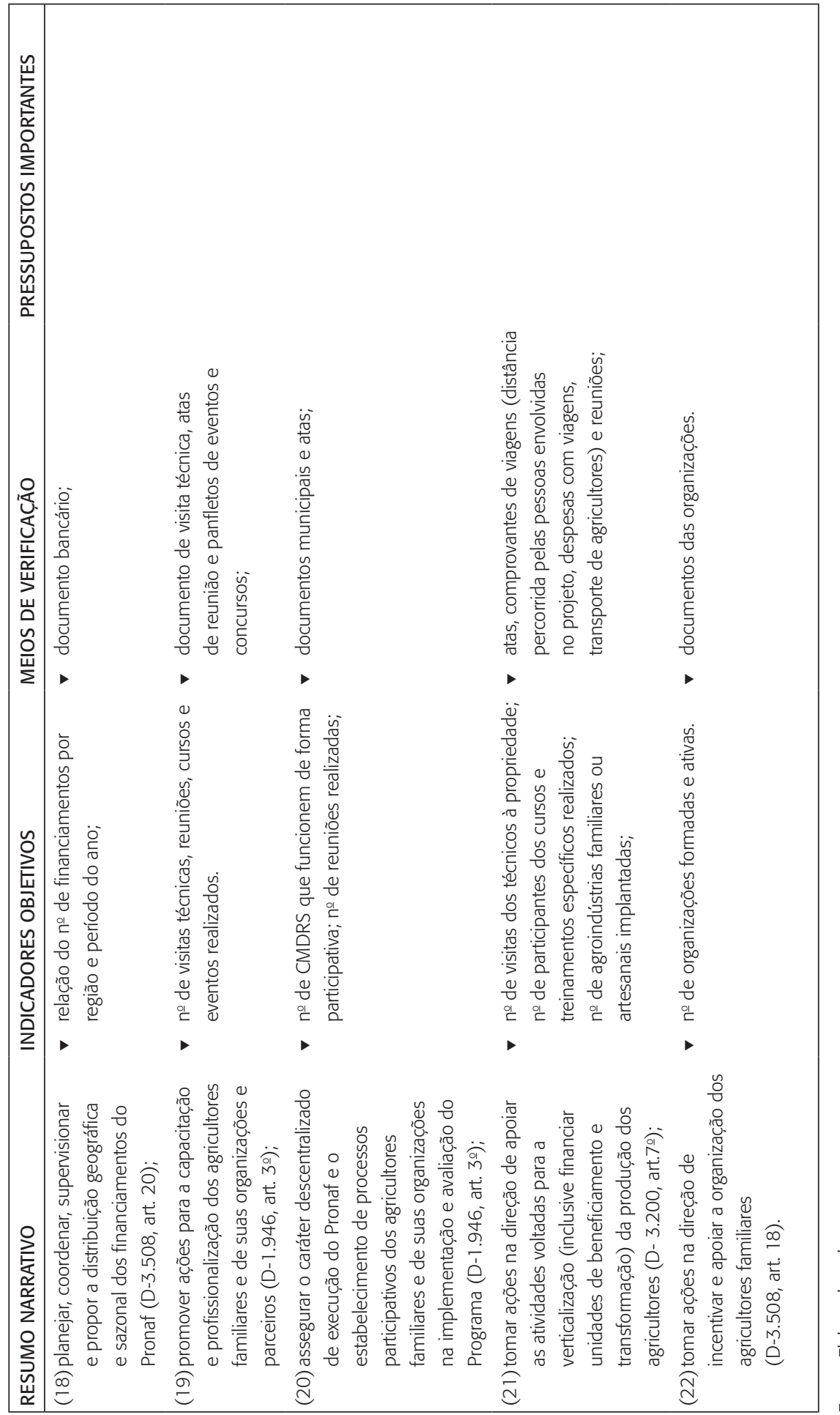

Rev. Adm. Pública - Rio de Janeiro 48(3):721-743, maio/jun. 2014 
Inicia-se a discussão da matriz proposta com os "insumos", que são as atividades de execução prática do projeto. Observou-se, no elenco desses, a insistente proposta de descentralização do poder aliada à participação dos beneficiários na construção da política. Essa descentralização inclui a adesão voluntária dos estados e municípios ao programa, um "pressuposto" que deveria estar explícito no programa — para uma avaliação completa, inclusive dos riscos envolvidos - e não está. A não inserção de nenhum pressuposto conduz à ideia de que não haveria risco envolvido no projeto (os produtos ocorreriam, uma vez que os insumos fossem realizados), o que é falso. Há riscos envolvidos e precisariam estar explícitos em algum documento sobre o programa, ainda que não na referida legislação.

Os documentos analisados não sugerem "indicador objetivo" e tão pouco "meios de verificação". Torna-se, portanto, difícil a avaliação precisa do cumprimento das ações propostas pelo programa. Essas falhas indicam - assim como a ausência dos pressupostos explícitos que o Pronaf apresenta inconsistência, quando avaliado pela estrutura lógica. A proposta dos indicadores objetivos e meios de verificação colabora para: (a) frustrar (ou pelo menos tornar mais difícil) ações clientelistas e paternalísticas; (b) dar orientação aos técnicos para que se cumpra exatamente o que a política propõe, e (c) desestimular a formação de conselhos falsamente participativos.

Alguns dos indicadores objetivos sugeridos são facilmente obtidos e precisam ser elaborados. É o caso dos indicadores tanto para insumo "7" quanto para produto "e" (no de produtores que permanecem na atividade ao longo dos anos, e no de produtores que tenham reduzido sua necessidade de subsídios). Os indicadores objetivos sugeridos para a maioria das atividades (quadro 2) quantificam participantes, visitas técnicas e reuniões. Não garantem em termos qualitativos - que esteja ocorrendo, de fato, o planejamento participativo ou a adequada difusão de tecnologia. Esses indicadores seriam uma forma de mensurar a execução do insumo. A questão de existir, de fato, o planejamento participativo ou a difusão adequada de tecnologia seria um pressuposto. Na matriz proposta, esses pressupostos aparecem, respectivamente em: "conselhos formados funcionem de modo realmente participativo", e "existam técnicos devidamente capacitados e dispostos a trabalhar com agricultura familiar", que constam entre os três últimos pressupostos no primeiro nível hierárquico da matriz.

Quanto aos meios de verificação, o quadro 2 apresenta como sugestões documentos bancários, notas fiscais, atas de reuniões, comprovantes de viagens, listas de presença, manual de crédito rural, panfletos, informações oriundas de pesquisa e até mesmo as contas do Estado. Entende-se que a lista não esteja esgotada, que outras sugestões surgirão à medida que a presente proposta de avaliação seja considerada por analistas de políticas públicas de diferentes formações.

Com relação aos objetivos de níveis hierárquicos mais elevados ("fim" e "propósito") tiveram sua ordem alterada na matriz proposta (quadro 2) em relação ao sugerido pelos formuladores da política e que constam no Decreto no 1.946, de 28 de junho de 1996. O fato se deve à ordem de que os objetivos foram apresentados no documento no qual, ao que parece, sugere-se que o desenvolvimento promova o aumento da capacidade produtiva e consequente melhoria de renda e qualidade de vida ao agricultor familiar. Neste estudo, com base na 
literatura analisada, e considerando-se que o Pronaf parece mais relevante em municípios pobres, entende-se - ao contrário do proposto pelo documento - que o aumento da produção (crescimento econômico) precede a melhoria da qualidade de vida (desenvolvimento). Admite-se, evidentemente, que a qualidade de vida possa advir de programas sociais, mas não seria sustentável. É o caso de programas que objetivam a assistência social, mas não têm relação com a capacitação do trabalhador ou geração de renda por parte dos beneficiados. Indiscutivelmente, o recurso permite melhoria de vida desses e pode movimentar o comércio local em pequenos municípios, mas esse impacto não garante a sustentabilidade do crescimento e do desenvolvimento por manter o gargalo do baixo estoque de capital humano e por criar condições propícias para manutenção do clientelismo, também de capital social.

O objetivo de mais alta hierarquia, o fim: “desenvolvimento sustentável do segmento rural", é um objetivo maior que o Pronaf. Outros projetos deverão ser bem-sucedidos para que se alcance tal objetivo. O PIB agropecuário foi um dos indicadores objetivos sugeridos para se verificar o cumprimento do objetivo. Com base na literatura analisada e as particularidades do Brasil, admite-se o crescimento do PIB municipal como condição necessária — mas não suficiente - para que se alcance o desenvolvimento. Ainda que as teorias de crescimento e desenvolvimento não sejam dissociadas - como foram no passado, anteriormente aos modelos endógenos de crescimento e, mais recentemente, com o trabalho de Putnam —, a condição inicial dos municípios nos quais o Pronaf é relevante justifica o uso desse indicador. Todavia, ressalta-se, o segmento rural não estaria a caminho do desenvolvimento sustentável com um alto PIB setorial e, simultaneamente, com um alto índice de degradação ambiental. Nem mesmo, por exemplo, sem as melhorias nas condições de saúde no meio rural.

A sugestão desses indicadores deve-se, em grande parte, às informações trocadas com técnicos que trabalham a serviço da agricultura familiar. É o caso de: (i) no de produtores que permanecem na atividade ao longo dos anos; (ii) $\mathrm{n}^{\circ}$ de produtores que tenham reduzido sua necessidade de subsídios; (iii) no de visitas dos técnicos à propriedade; (iv) no de participantes dos cursos e treinamentos realizados, e (v) no de solicitações (de serviços de Ater) efetuadas e atendidas dos agentes financeiros. A partir dos diálogos com os técnicos, verificou-se que esses não conheciam claramente os objetivos do Pronaf, limitavam-se a dominar apenas a excessiva burocracia do sistema bancário. Apontaram o próprio despreparo para trabalhar com a agricultura familiar, uma vez que não são oferecidos cursos para tal especificação. Talvez esse despreparo possa ser consequência da falta de tradição em políticas mais democráticas no Brasil, ao longo de décadas. E ainda, mais recentemente, das poucas disciplinas de ciências humanas no currículo dos profissionais das ciências agrárias, o que, associadas à origem urbana de grande parte dos técnicos do setor, agrava a dificuldade.

Como já exposto, os pressupostos sugerem os riscos de que, mesmo atingindo os objetivos de hierarquia mais baixa, os objetivos de hierarquia imediatamente superior não aconteçam. Dentre os primeiros pressupostos (linha "insumos", coluna "pressupostos importantes"), destaque é dado ao pressuposto de que as políticas públicas não apresentem externalidades negativas com relação ao Pronaf. Por exemplo, supondo-se que as políticas educacionais favoreçam a construção de escolas e centros de capacitação profissional de qualidade, e tais 
estruturas estejam em centros urbanos. Nessa hipotética situação, se não for facilitado o transporte dessa população rural para esses locais, pode-se excluí-la desse processo de formação de capital humano. Nesse caso, uma política bastante interessante teria gerado uma externalidade negativa em relação aos moradores de áreas rurais. Ou ainda, se houvesse, de fato, a inclusão dessa população rural em tais políticas educacionais, essa se interessaria em ficar no campo? Ou vislumbraria outras possibilidades de crescimento nas cidades? Se assim fosse, haveria frustração da concretização dos produtos "b", "c", "d" e "k" e, indiretamente, os demais objetivos.

Em síntese, embora o Pronaf apresente propostas condizentes como perfil das políticas da década de 1990, pelo método da estrutura lógica verificou-se que o projeto não é apresentado de forma consistente. Como explanado no quadro 2, obteve-se, a partir dos documentos citados, os insumos, produtos, propósito e fim. A partir dos documentos analisados — Brasil (1996), Brasil (1999) e Brasil (2000) —, não foi possível obter, em nenhum nível hierárquico da matriz: (i) pressuposto explícito, (ii) indicador objetivo, e (iii) meio de verificação. A não explicitação dos pressupostos compromete a avaliação da exequibilidade dos objetivos que propõem melhorar a qualidade de vida dos agricultores familiares e a promoção do desenvolvimento rural sustentável.

\section{Considerações finais}

O Pronaf, criado no contexto de democratização, incluiu o acesso dos mais pobres ao capital financeiro. A legislação que o criou está em conformidade com os avanços da literatura sobre desenvolvimento econômico, cuja ênfase recai na participação da população interessada e no estímulo à formação de capital social. A existência obrigatória dos Conselhos Municipais de Desenvolvimento Rural indica essa conformidade.

A análise do Pronaf, por metodologia utilizada por agências internacionais financiadoras de projetos de desenvolvimento e ajuda humanitária, indicou inconsistência. Discordar disso é discordar do método utilizado ou, o que é razoável, pensar que o programa deva ter um documento formal, um projeto. Não foi encontrado tal documento, mas indicações da sua inexistência. A inconsistência, de acordo com a metodologia utilizada, ocorre em um projeto quando ele não preenche toda a matriz de estrutura lógica. Ainda que não seja um projeto, e sim um programa, a metodologia possibilitou evidenciar aspectos quantitativos importantes. Elaborou-se, no presente estudo, uma proposta de estrutura lógica para o Pronaf.

A metodologia da estrutura lógica contribuiu para ordenar os objetivos do Pronaf em um sequenciamento lógico e elucidar pressupostos importantes. Tal ordenamento permitiu, também, que fossem propostos indicadores objetivos e meios de verificação. Ainda que avaliações qualitativas não sejam possíveis com tal método, o preenchimento das colunas da matriz com esses itens agregou maior profundidade e compreensão do Pronaf, bem como de suas limitações. Quanto aos objetivos do Pronaf, foi possível construir a ordenação lógica.

As propostas do Pronaf objetivam o desenvolvimento rural sustentável, almejando a melhoria da qualidade de vida dos agricultores familiares (o "propósito" do programa). Para 
o cumprimento desse propósito, as ações do programa consideram, implicitamente, a relevância da formação de capital humano e social no meio rural. A tentativa de formar esses estoques, no programa, relaciona-se às atividades ligadas ao incentivo a associações, conselhos e cooperativas rurais, e serviços de Assistência Técnica e Extensão Rural (Ater) para os produtores familiares.

Enfim, o programa avança ao propor o planejamento participativo, correspondendo às tendências democráticas. A partir dos objetivos do programa, constatou-se que o Pronaf é um instrumento de política mais sensível à demanda de seus beneficiários, com relação às políticas agrícolas antes dos anos de 1990. A ausência de um documento formal, um projeto de desenvolvimento, detectada na pesquisa, prejudica a análise dos resultados do Pronaf. A utilização da legislação para a elaboração de uma matriz, no presente estudo, possibilitou uma proposta para preencher esta lacuna.

\section{Referências}

ABRAMOVAY, Ricardo. Conselhos além dos limites. Estudos Avançados, v. 15, n. 43, p. 121-140, set./dez. 2001. Disponível em: < http://dx.doi.org/10.1590/S0103-40142001000300011>. Acesso em: 12 maio 2011.

ABRAMOVAY, Ricardo. O capital social dos territórios: repensando o desenvolvimento rural. Economia Aplicada, v. 4, n. 2, p. 379-397, 2000.

ALVES, Eliseu. Tecnologia e preservação são irmãs gêmeas. Agroanalysis, v. 32, n. 9, p. 6-8, set. 2012.

ALVES, Eliseu A. A agricultura familiar. Revista de Política Agrícola, v. 6, n. 3, p. 28-32, 1997.

ARAÚJO, Paulo F. C.; ALMEIDA, Alivinio. Financiamento da agricultura: evolução e perspectivas. Preços Agrícolas, v. 11, n. 2, p. 3-8, 1997.

ARAÚJO, Paulo F. C.; SHIROTA, Ricardo. Crédito e desenvolvimento da agricultura. In: CONGRESSO BRASILEIRO DE ECONOMIA E SOCIOLOGIA RURAL, 25, Brasília. Anais... Brasília: Sober, 1987. p. 99-112.

BERNARDES, Elaine M. Desenvolvimento do vale do Tietê-Paraná: um enfoque de capitais. Tese (doutorado) - Escola Superior de Agricultura "Luiz de Queiroz", Piracicaba, 2002.

BERNARDES, Elaine M.; PERES, Fernando C. Análise dos projetos de desenvolvimento dos vales dos rios Tietê e Paraná. Rev. Adm. Pública, Rio de Janeiro, v. 40, n. 2, p. 237-52, 2006.

BRASIL. Decreto no 1.946, de 28 de junho de 1996. Dispõe sobre a criação do Programa Nacional de Fortalecimento da Agricultura Familiar. JusBrasil. Disponível em: <www.jusbrasil.com.br/ legislacao/112235/decreto-1946-96>. Acesso em: 14 fev. 2012. 
BRASIL. Decreto no 3.200, de 6 de outubro de 1999. Dispõe sobre o Conselho Nacional de Desenvolvimento Rural. Código Civil. Disponível em: <http://www.planalto.gov.br/ccivil_03/decreto/ D3200.htm>. Acesso em: 16 fev. 2012.

BRASIL. Decreto no 3.508 , de 14 de junho de 2000. Dispõe sobre o Conselho Nacional de Desenvolvimento Rural Sustentável — CNDRS, e dá outras providências. Disponível em: <www.planalto. gov.br/ccivil_03/decreto/D3508.htm>. Acesso em: 16 fev. 2012.

BRASIL. Plano safra da agricultura familiar 2013/14 terá 39 bilhões. 2013. Disponível em: <www2. planalto.gov.br/imprensa/noticias-de-governo/governo-anuncia-investimentos-de-mais-de-r-39bilhoes-para-a-agricultura-familiar >. Acesso em: 10 jun. 2013.

CAMPOS, Simone V. Conflitos envolvendo recursos de uso comum em áreas de proteção integral: o caso do acordo de pesca do Rio Unini, no Parque nacional do Jaú, AM. In: ENCONTRO ANUAL DAANPOCS, 28., 2004, Caxambu. Anais... Caxambu: s.n., 2004. p. 417-432.

CARDOSO, João L. Política de crédito rural no Brasil: uma análise dos estatísticos de 1983 a 1985. In: ENCONTRO DOS GRUPOS TEMÁTICOS DO PROJETO DE INTERCÂMBIO DE PESQUISA SOCIAL EM AGRICULTURA, 13., 1988, Botucatu. Anais...Botucatu: Unesp FCA/ Departamento de Economia Rural, 1988. p. 773-801.

CASTILHOS, Dido S. B. Capital social e políticas públicas: um estudo da linha infraestrutura e serviços aos municípios do Programa Nacional de Fortalecimento da Agricultura Familiar. Dissertação (mestrado) — Universidade Federal do Rio Grande do Sul, Porto Alegre, 2002.

COLEMAN, Gilroy. Logical framework approach to the monitoring and evaluation of agricultural and rural development projects. Project Appraisal, v. 2, n. 4, p. 252-259, 1987.

COLEMAN, James S. Social capital. In: COLEMAN, James S. Foundations of social theory. Cambridge: The Belknap Press of Harvard University Press, 1990. p. 300-321.

DOMAR, Evsey D. Capital expansion, rate of growth and employment. Econometrica, v. 14, n. 2, p. 137-147, 1946.

GUANZIROLI, Carlos E. Pronaf dez anos depois: resultados e perspectivas para o desenvolvimento rural. Rev. Econ. Sociol. Rural, v. 45, n. 2, p. 301-328, 2007.

HARROD, Roy F. An essay in dynamic theory. Economic Journal, v. 49, n. 193, p. 14-33, 1939.

HOMEM DE MELO, Fernando. Ainda explicando o bom desempenho agrícola recente. 2010. Disponível em: <hwww.fipe.org.br/publicacoes/downloads/bif/2010/10_bif361.pdf>. Acesso em: 12 set. 2011.

JACKSON, Bill. Designing projects and projects evoluations using the logical framework approach. UCN Monitoring and Evaluation Inatiative, out. 1997. Disponível em: < http://cmsdata.iucn.org/ downloads/logframepaper3.pdf>. Acesso em: 23 abr. 2012.

JOHNSTON, Bruce F.; MELLOR, John W. The role of agriculture in economic development. American Economic Review, v. 51, n. 4, p. 567-593, set. 1961. 
LUCAS, Robert E. On the mechanics of economic development. Journal of Monetary Economics, v. 22, n. 1, p. 3-42, 1988.

MATTEI, Lauro. Impactos do Pronaf: análises de indicadores. Brasília: Nead Estudos, 2005.

MEYER, Leandro F. F.; BRAGA, Marcelo J. Governança além do Homo Economicus. In: ENCONTRO NACIONAL DA ECOECO, 7., 2007, Fortaleza. Anais... Fortaleza: s.n., 2007. p. 1117-1123.

PEREIRA, Eder L.; NASCIMENTO, Jean S. Agricultura familiar e crédito rural: dimensões econômicas básicas e impactos do programa nacional de fortalecimento da agricultura familiar (Pronaf) no estado do Tocantins-Brasil. In: CONGRESSO BRASILEIRO DA SOBER, 50., 2012, Vitória. Anais... Vitória: s.n., 2012. p. 291-307.

PERES, Fernando C.; CANZIANI, José R.; GUIMARÃES, Vania D. A. Programa Empreendedor Rural. Paraná: Sebrae, 2009. p. 189-217.

PRUGH, Thomas. Natural capital and human economic survival. Solomons: International Society for Ecological Economics, 1995.

PUTNAM, Robert D. Making democracy work: civic traditions in modern Italy. Princeton: Princeton University Press, 1993.

REZENDE, Gervásio C. Política agrícola, preço da terra e estrutura agrária. In: CONGRESSO BRASILEIRO DE ECONOMIA E SOCIOLOGIA RURAL, 25., 1987, Brasília. Anais... Brasília: Sober, 1987. p. $73-126$.

ROMER, Paul M. Endogenous technological change. Journal of Political Economy, v. 98, n. 5, p. S71-S102, 1990.

ROMER, Paul M. Increasing returns and long-run growth. Journal of Political Economy, v. 94, n. 5, p. 1002-1037, 1986.

RUTTAN, Vernon W. Catching up and falling behind. In: RUTTAN, Vernon W. Technology, growth, and development: an induced innovation perspective. Nova York: Oxford University Press, 2001. cap. 2, p. 15-60.

SACHS, Ignacy. Rumo a uma moderna civilização baseada em biomassa. In: SACHS, Ignacy. Caminhos para o desenvolvimento sustentável. Rio de Janeiro: Garamond, 2002. cap. 1.

SCHUH, George E. Modernização e dualismo tecnológico na agricultura: alguns comentários. Pesquisa e Planejamento Econômico, Rio de Janeiro, v. 3, n. 1, p. 51-94, mar. 1973.

SCHUH, George E. The economic organization of world agriculture. In: SEMINÁRIO DO DEPARTAMENTO DE ECONOMIA, ADMINISTRAÇÃO E SOCIOLOGIA DA ESCOLA SUPERIOR DE AGRICULTURA “LUIZ DE QUEIROZ”, 1998, Piracicaba.

SCHULTZ, Theodore W. A transformação da agricultura tradicional. Rio de Janeiro: Zahar, 1965. SEN, Armatya. Desenvolvimento como liberdade. São Paulo: Companhia das Letras, 2000. 
SILVA, Jorge L. M.; PAULA, Érika K. L. Políticas públicas para agricultura familiar: uma análise da correspondência entre o PAA e o Pronaf nos territórios da cidadania do Rio Grande do Norte, 2008 a 2010. In: CONGRESSO BRASILEIRO DA SOBER, 50., 2012, Vitória. Anais... Vitória: s.n., 2012. p. 2012-2043.

SOLOW, Robert. A contribution to the theory of economic growth. Quarterly Journal of Economics, v. 70, n. 1, p. 65-94, 1956.

SOLOW, Robert. Technical change and the aggregate production function. Review of Economics and Statistics, v. 39, n. 3, p. 312-320, 1957.

STERN, Nicholas. Growth theories, old and new, and the role of agriculture in economic development. Londres: London School of Economics, 1994.

STERN, Nicholas. Stern review: the economics of climate change. UK: s.n., 2006.

VEIGA, José E. Como pode ser medida a sustentabilidade. In: VEIGA, José E. Desenvolvimento sustentável: o desafio do século XXI. Brasília: Ministério do Desenvolvimento Agrário, 2005. p. 173-184.

VEIGA, José E. O Brasil rural precisa de uma estratégia de desenvolvimento. Brasília: Convênio FipeIica (MDA/CNDRS/Nead), 2001.

Evandro Henrique Figueiredo Moura da Silva é engenheiro agrônomo pela Unesp — Univ. Estadual Paulista, Campus de Ilha Solteira. E-mail: ehfmsilva@gmail.com.

Elaine Mendonça Bernardes é engenheira agrônoma, mestre e doutora em economia aplicada pela Esalq/ USP, professor assistente doutor da Unesp — Univ. Estadual Paulista, Campus Experimental de Dracena. E-mail: emb@dracena.unesp.br. 
